\title{
ESTUDIO SOBRE LAS PALLOZAS DE LA SIERRA DE LOS ANCARES/ESPAÑA*
}

\author{
(STUDY OF THE "PALLOZAS" IN THE "SIERRA DE LOS ANCARES"ISPAIN)
}

\author{
Francisco A. González Fernández, Dr. en Filosofia y Letras \\ Madame Peyrègne et Mr. Serrano: Directeurs de Recherches \\ Catedráticos de la Universidad de Paris III, Sorbonne
}

\section{RESUMEN}

El objeto de este trabajo es dar a conocer la existencia, en una pequeña zona de montañas, del noroeste de España, de un tipo de construcciones arcaicas, las pallozas, que tienen gran parecido con los primeros hábitat construidos por el hombre en la Península Ibérica hace más de 2000 años.

El avanzado deterioro y la posible desaparición de las pallozas llevó al autor a realizar un estudio, sobre las mismas, con el fin de conocerlas mejor y de que no cayesen definitivamente en el olvido.

\section{SUMMARY}

The object of this work is to make known the existence, in a small mountain area of the north-west of Spain, of a form of archaic constructions, the "Pallozas", that have a great similarity to the first habitat built by man in the Iberian Peninsula more than 2000 years ago.

The advanced deterioration and the possible disappearance of the "Pallozas" led the author to realize a study of the same in order to get to know them better and to prevent their definite falling into oblivion.

\section{INTRODUCCION}

El estudio sobre las pallozas (hábitat construidos por el hombre en la Península Ibérica hace más de 2000 años) se llevó a cabo mediante un reconocimiento de la zona tomando contacto con sus habitantes, lo cual no resultó fácil debido a que desconfian de los forasteros que hacen preguntas y quieren ver el interior de sus casas. Posteriormente se consultó la documentación necesaria sobre las construcciones redondas del noroeste de España en general, y de las pallozas en particular. Por último, y lo más importante, fue realizar un trabajo de campo con objeto de poder confrontarlo con la documentación que hace referencia a las pallozas. Todo esto ha dado como resultado una serie de datos inéditos que, muy someramente, se presentan en este trabajo.

La participación en las tareas de restauración, realizadas en Campo del Agua (León) durante los veranos de 1986 y 1987, facilitó la recopilación de datos y la preparación de dibujos y fotografías, parte de los cuales ilustran este artículo.

\footnotetext{
*Tesis leída en París, el 20-10-86.

Obtuvo la calificación de Apto con notable.
}

Hasta hace unos diez años las comunicaciones de los Ancares con el exterior eran muy dificiles: accesos existentes en mal estado, pueblos sin luz, sin teléfono, sin carreteras. Los medios de transporte de viajeros eran prácticamente inexistentes. Las estaciones de ferrocarril más próximas, Ponferrada, León y Lugo, se sitúan a unos $60 \mathrm{~km}$. Los autobuses de línea no garantizan un servicio en la región. Era normal que la gente anduviese distancias de 20 a $30 \mathrm{~km}$ de ida y otros tan-

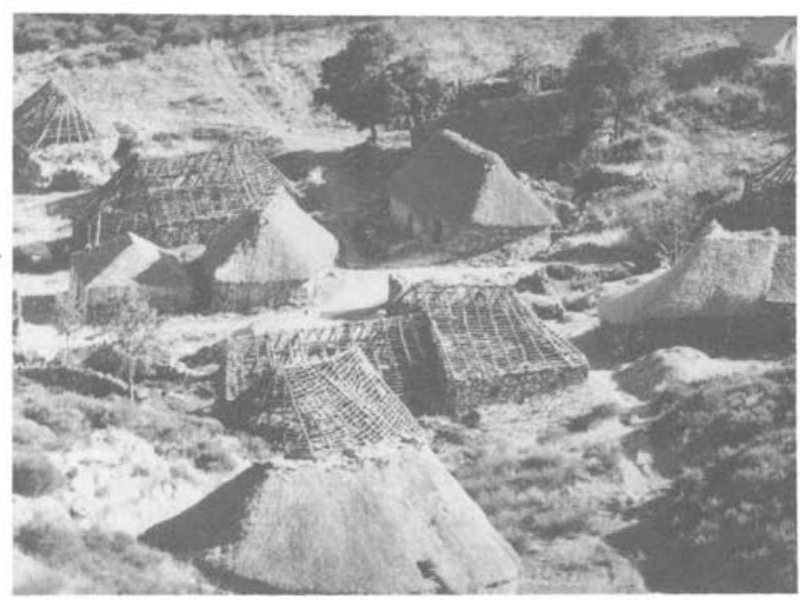

Restauración en Campo del Agua. 


\section{PALLOZA ANTIGUA DE PIORNEDO. SISTEMA DE CUBIERTA MAS ANTIGUO A BASE UNICAMENTE DE ESTEOS (NO HAY TIXEIRAS)}

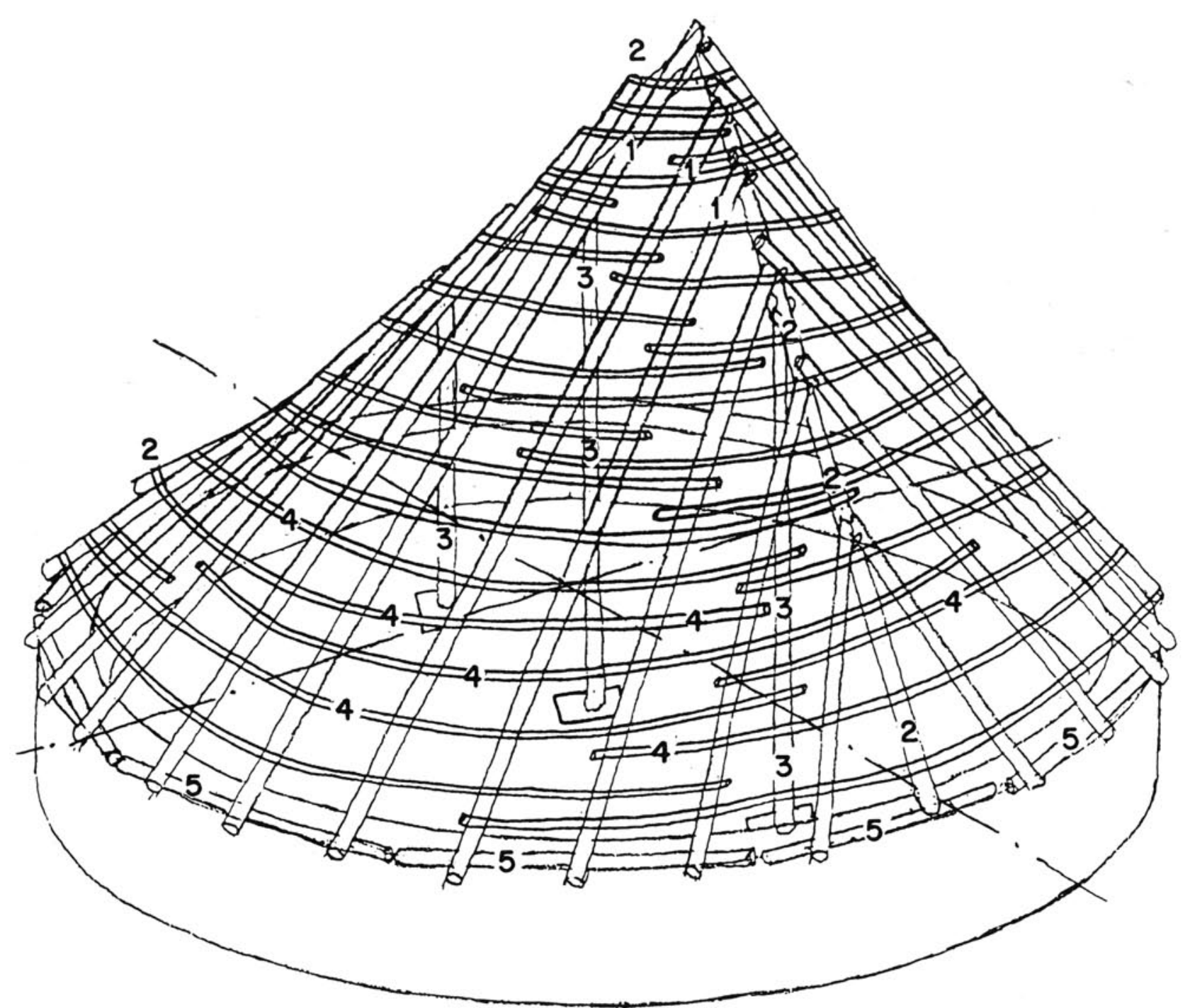

Estas pallozas suelen ser las más pequeñas, ya que de lo contrario hubiera sido necesario utilizar troncos de árboles cada vez más largos y gruesos.

1. Cango - 2. Cume - 3. Esteo - 4. Ripia - 5. Suleira

tos de vuelta en el dia, para ir al médico, ferias, etc. Este aislamiento produjo un atraso cultural y económico grave. Esto, unido a la pobreza del terreno y a la dureza de la vida en estas montañas, trajo como consecuencia sucesivas oleadas de emigración entre los años 50 y 70 .

En estos últimos diez años las comunicaciones por carretera han mejorado mucho. En la vertiente lucense se hicieron dos carreteras importantes comunicando muchos pueblos entre sí. En la vertiente leonesa se continuó la carretera a través de varios pueblos, pasando por el impresionante puerto Viejo de Antelo $1.684 \mathrm{~m}$. De esta manera quedaba terminada la primera vía de comunicación entre las dos vertientes que cruza la sierra. La segunda vía se terminó en 1986.
Esta rápida evolución en la mejora de infraestructuras de acceso, luz y teléfono, se ha debido, en gran parte, al interés despertado por las pallozas en las Administraciones de las provincias de León y Lugo.

\section{Aspectos generales}

Las pallozas son, quizás, las viviendas más curiosas y llamativas del noroeste, por sus formas redondas $u$ ovales, así como por constituir un ejemplo raro, aunque no único dentro de la arquitectura popular española.

La palloza es una construcción de piedra, de muro circular bajo, con una gran cubierta de paja de centeno http://informesdelaconstruccion.revistas.csic.es 


\section{PALLOZA CON UNA ESTRUCTURA A BASE DE ESTEOS Y TIXEIRADO}

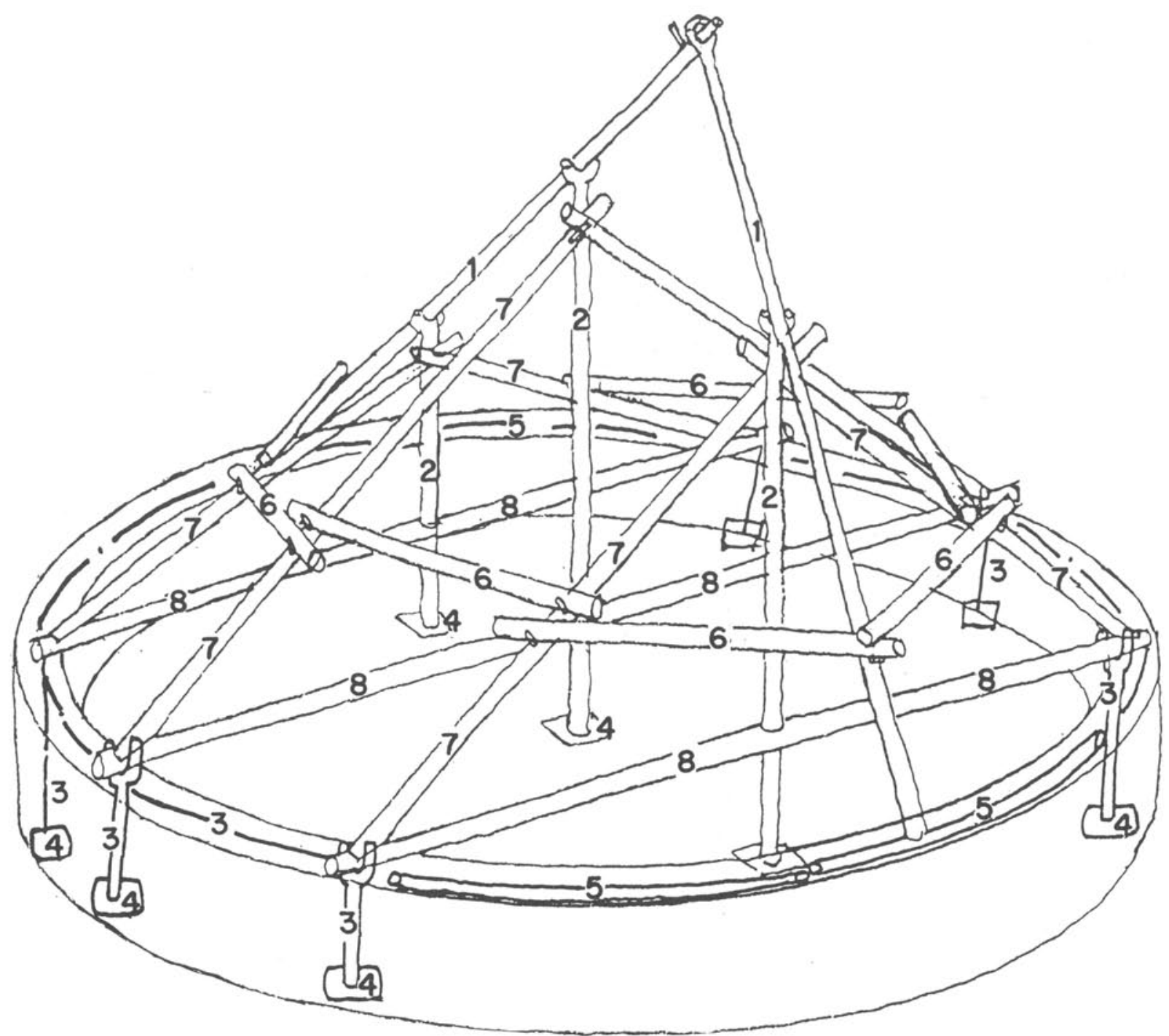

Caracteristica de Piornedo, Xantes, Cantejeira, Paradaseca y Vilarello. La multiplicación de esteos y tixeiras permite hacer pallozas mayores. 1. Cume-2. Esteo-3. Forcado-4. Piedra plana-5. Suleira-6. Tercia-7. Tixeira-8. Viga madre de la tixeira

y el armazón de madera. En la mayoría de ellas el muro sólo sirve como cerramiento, ya que toda la estructura del techo se apoya en pilotes de madera de roble que lo hacen autoportante. La palloza ha sido y aún sigue siendo, en algunos casos, la casa completa de los ancareses. Un gran habitáculo de una sola planta dividido interiormente con tablas y palos, donde las personas hacen su vida hogareña al lado de sus animales en intima vecindad.

Los únicos vanos son los constituidos por la puerta de entrada, que suele estar entre la cuadra y el hogar, y la puerta de dos hojas de la cuadra, más ancha con el fin de permitir la entrada del carro.
El techo no tiene salida de humos, puesto que la construcción carece de chimenea. Modernamente, a algunas pallozas se les ha practicado algún ventano en la pared con el fin de recibir más luz del exterior, pero esto no es propio de la construcción. Por consiguiente, el interior es muy oscuro, dado que la única luz que tiene es la que recibe por la puerta. Ahora bien, el hecho de tener pocos vanos hace que el interior sea muy fresco en verano y relativamente fácil de calentar en invierno, por constituir todo el aposento un espacio cerrado.

Hoy en dia, pocas pallozas se usan para su función original, que era vivienda para las personas, cobijo para sus animales, y almacén para las cosechas cuando no se disponia de un hórreo. 


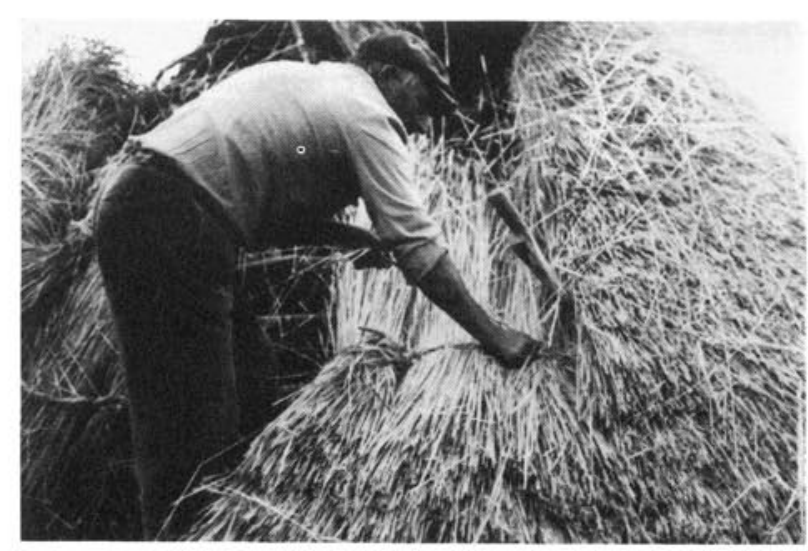

Poniendo la paja

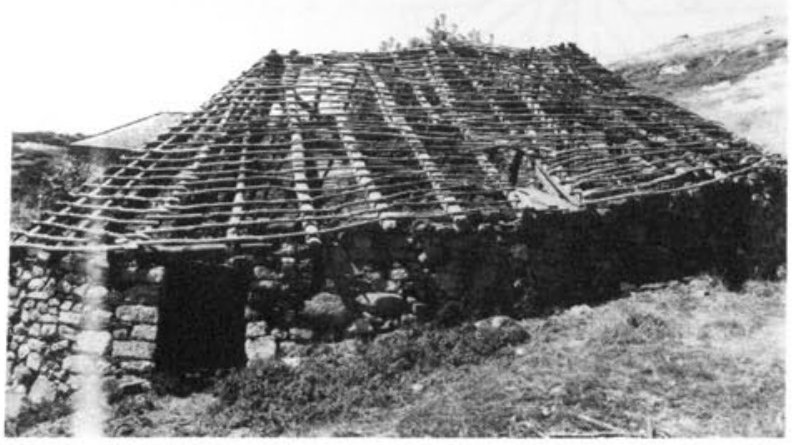

Palloza "ripiada"
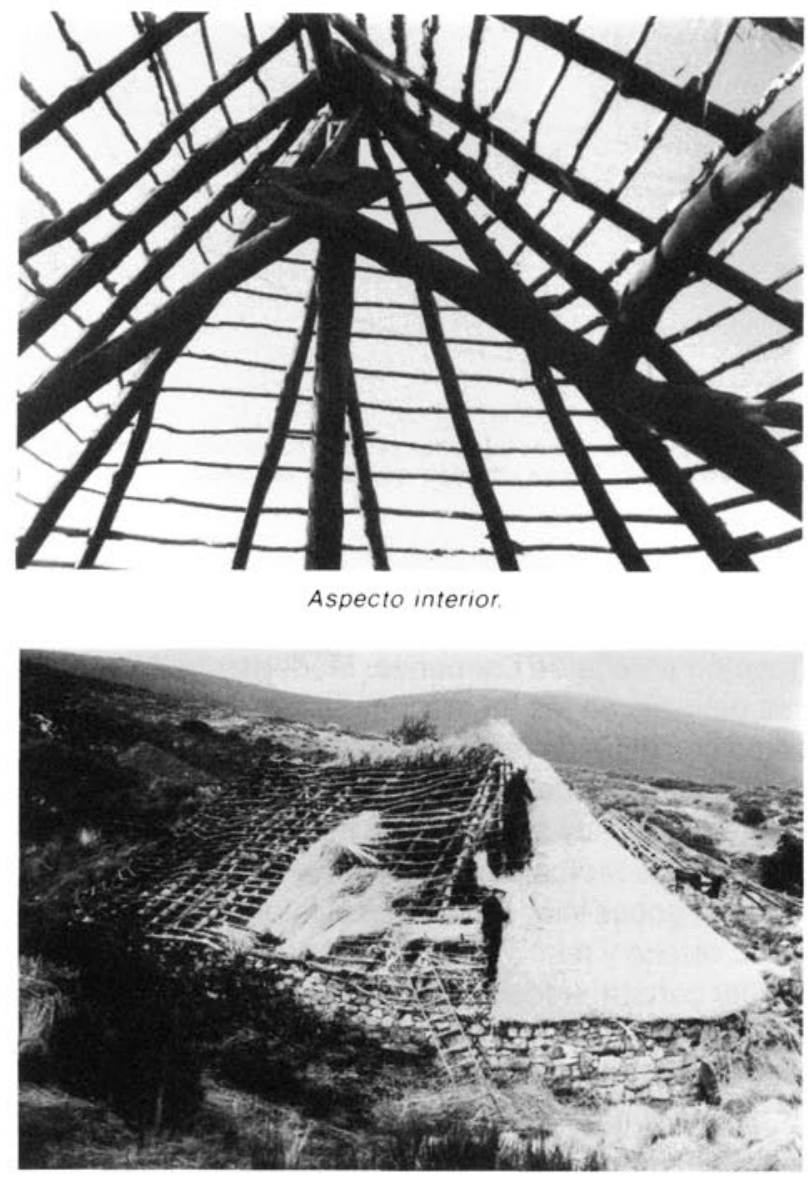

Aspecto exterior.

(C) Consejo Superior de Investigaciones Científicas

Licencia Creative Commons 3.0 España (by-nc)

\section{Construcción}

En primer lugar, para construir una palloza se allana el terreno en dos bancales. El mayor, que es el que está en la parte más baja, es el destinado a los animales, y el otro, algo más pequeño, es el de las personas. Una vez preparado el terreno se colocan unas piedras planas que servirán de base a los esteos y a los forcados. Los esteos ayudarán a sostener el cume. Los forcados se distribuyen según el número de tixeiras, que tenga la palloza (una palloza pequeña tendrá dos tixeiras, una grande tres), y recibirán en su seno la viga madre de la tixeira. Se llaman vigas madres a las que atraviesan la palloza en su diámetro o perpendiculares al eje mayor de la misma. Estas vigas forman parte del tixeirado. De los extremos de las vigas madres arrancarán las dos vigas de una tixeira, juntándose en la parte más alta de la construcción, a unos cinco o seis metros del suelo, y formando un triángulo con la viga madre. El tixeirado recibe el cume, que es la viga más alta de la construcción que, paralela al suelo, reposa sobre las tixeiras. Las tixeiras están unidas, entre sí, por las tercias. Una vez levantado el tixeirado, y puesto el cume, se procede al cierre de la construcción por medio de un muro de piedra de unos $80 \mathrm{~cm}$ de ancho. Las piedras se tallan toscamente de manera que asienten unas con otras. Algunas pallozas construidas con piedras talladas a cincel son obra de maestros artesanos. Como argamasa se utiliza la arena de la misma piedra. Las piedras más grandes se colocan en las dos caras interior y exterior del muro y se va rellenando el muro por dentro con piedras más pequeñas si es necesario. La altura del muro puede variar de 0,50 a 2 m, esto depende de la inclinación del terreno si la palloza está construida sobre un plano inclinado. Se suele aprovechar el desnivel del terreno, de esta manera el muro será más bajo en la parte superior del plano (entre 0,50 y $1 \mathrm{~m}$ ) y más alto en la parte inferior (de 1 a 2 m). En el caso de una palloza construida sobre un plano totalmente Ilano, la altura del muro suele ser de unos $2 \mathrm{~m}$. El muro se remata con maderos de, aproximadamente, $2 \mathrm{~m}$ de largo ensamblados todo alrededor. Esto es lo que se llama la suleira. Una vez hecha la suleira se colocan, primero, unos tiradores que van a las tercias y, después, los cangos, empezando siempre por los que partiendo de los extremos del cume bajan en plano inclinado hacia los extremos de la palloza, en el sentido de su eje mayor. Después se colocan los demás radialmente. Todos los ensamblajes de unas vigas con otras, o de cangos entre sí, se realizan machihembrando unos palos con otros. A los machihembrados por el sistema de ranura y lengüeta se les clavan unos pinos con el fin de fijar ambos elementos. Actualmente, en la restauración, los pinos son sustituidos por clavos o puntas de hierro.

Una vez terminada la colocación de los cangos se ponen las ripias todo alrededor de la cubierta, empezando por la base y terminando en la parte superior. Antiguamente, las ripias se ataban con vilortos, pero, hoy 
día, esta operación llevaria demasiado tiempo, por esta razón, los teitadores utilizan la punta.

\section{Preparación de la paja y techado}

La descripción que sigue ha sido tomada del trabajo de restauración de los techos llevada a cabo durante los tres últimos años en el pueblo de Campo del Agua en la provincia de León, patrocinada por la Diputación de León y la Junta de Castilla y León.

Para construir un techo es necesaria la paja de centeno. Es el material más resistente y duradero. El centeno debe ser segado y quitado el grano, intentando evitar que la paja se rompa, por lo que no puede ser trillado. Hay que majarlo. Esta operación, se realizaba antiguamente con el mayal y hasta hace algunos años con la majadora, ya en desuso. En el resto del proceso únicamente intervienen las manos.

Una vez que a la paja se le ha retirado el grano, hay que escolmarla, sacudiendo poco a poco pequeñas cantidades para separar los hierbajos y pajas demasiado cortas o rotas. Es el trabajo más lento y pesado y el que requiere mayor cantidad de mano de obra, dado que hay que trasladar toneladas de paja (aproximadamente se desecha el $30 \%$ ). Con lo útil se hacen gavillas que se Ilaman cuelmos, con paja larga y entera $(1,50$ a $2 \mathrm{~m})$ que será la que se coloque en el techo. Antes de empezar a poner la paja se revisa el estado de las ripias. El teitador fabrica primero unas cuerdas de paja llamadas bincayos o vencellos. Primero moja una gavilla entera para que la paja no se rompa al manipularla y a continuación va tomando ocho o diez pajas en cada mano, las entrecruza por la parte de las espigas y comienza a retorcerlas hasta que dan la impresión de una tosca soga de $1,50 \mathrm{~m}$ de largo, aproximadamente. Con estos bincayos atará y fijará la paja.

La paja, la cubierta propiamente dicha, comienza a colocarse, lógicamente, por la parte inferior de la estructura. El teitador toma una porción de paja y la ata a las ripias en dos puntos, de manera que la espiga quede hacia arriba y el corte hacia abajo, sobresaliendo la paja unos $50 \mathrm{~cm}$ fuera de la pared, con el fin de que el agua no penetre en ella. Con una paleta llamada, teitello, de unos $80 \mathrm{~cm}$ de larga por 10 de ancha, y terminada en punta, golpea la paja suavemente por el corte con el fin de que asiente y tome homogéneamente la inclinación del techo. Hecho esto, toma otra porción de paja y la coloca de la misma manera encima de la anterior, de forma que tape los dos atados y la espiga; vuelve a atar de nuevo y a asentar con el teitello. Asi va repitiendo la operación hacia arriba, haciendo una andada de unos $40 \mathrm{~cm}$ de ancho y 10 mismo de grueso, todo lo que puede atar con un bincayo. Cuando termina una primera hilera vuelve a empezar una segunda, imbrican-

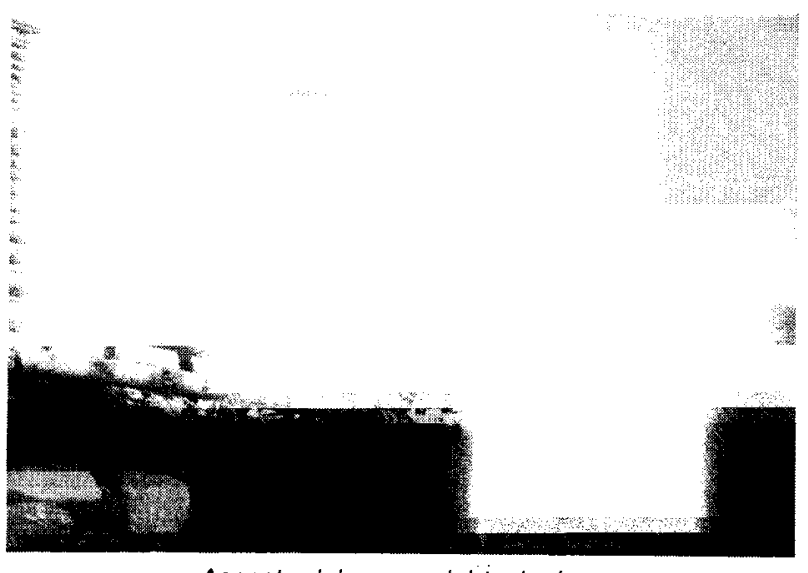

Aspecto del grosor del techado.

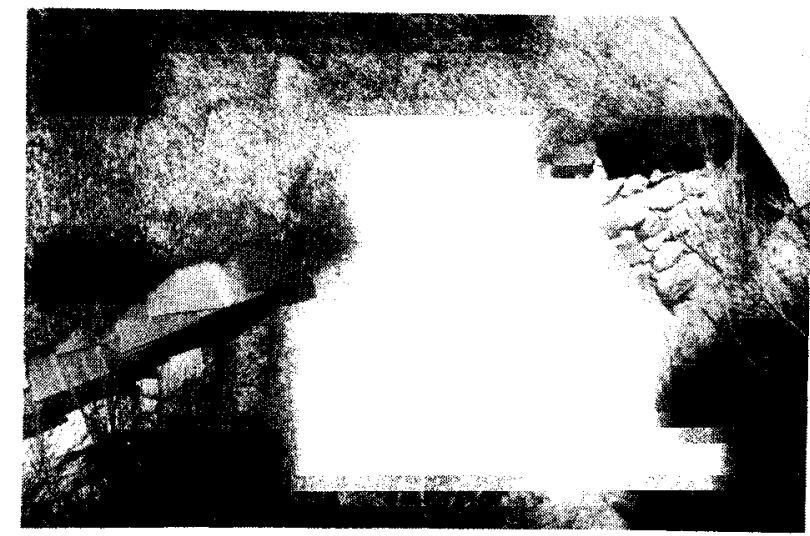

Gruesa roca aprovechada como apoyo y cerramiento.

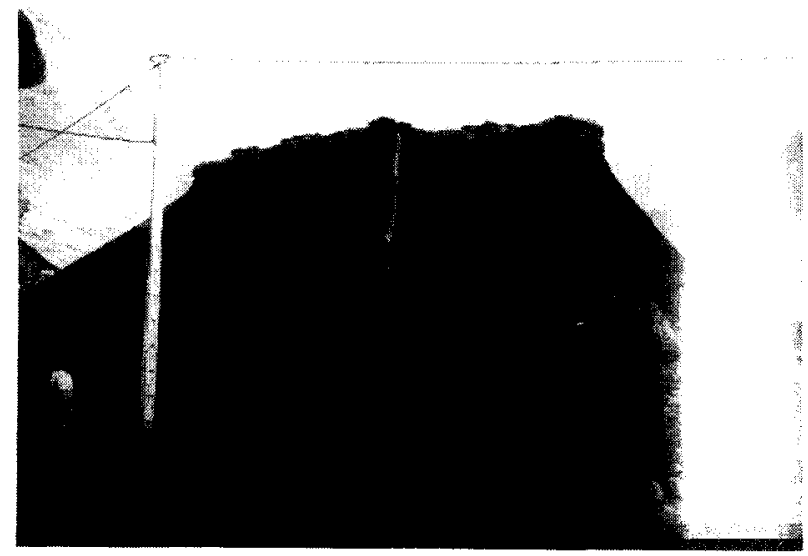

Balouta: "El progreso no respeta nada".

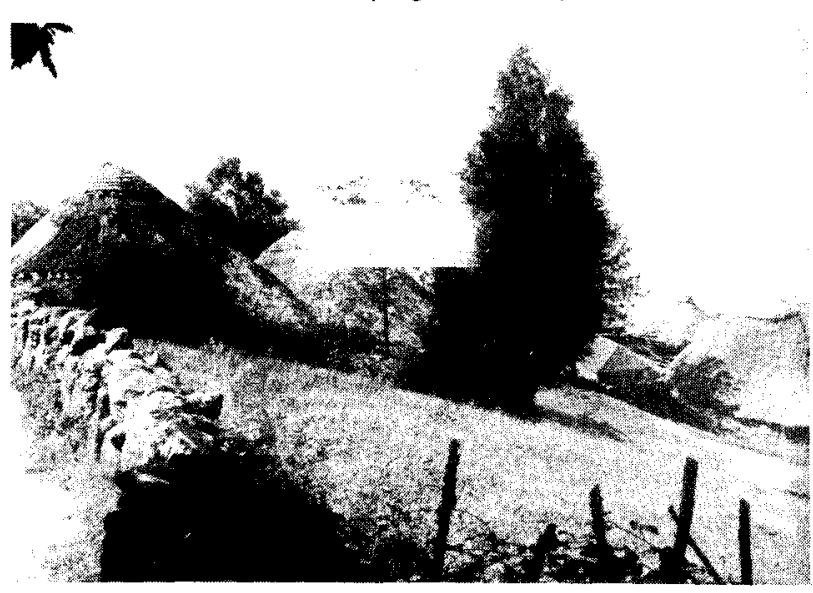

Piornedo.

http://informesdelaconstruccion.revistas.csic.es 


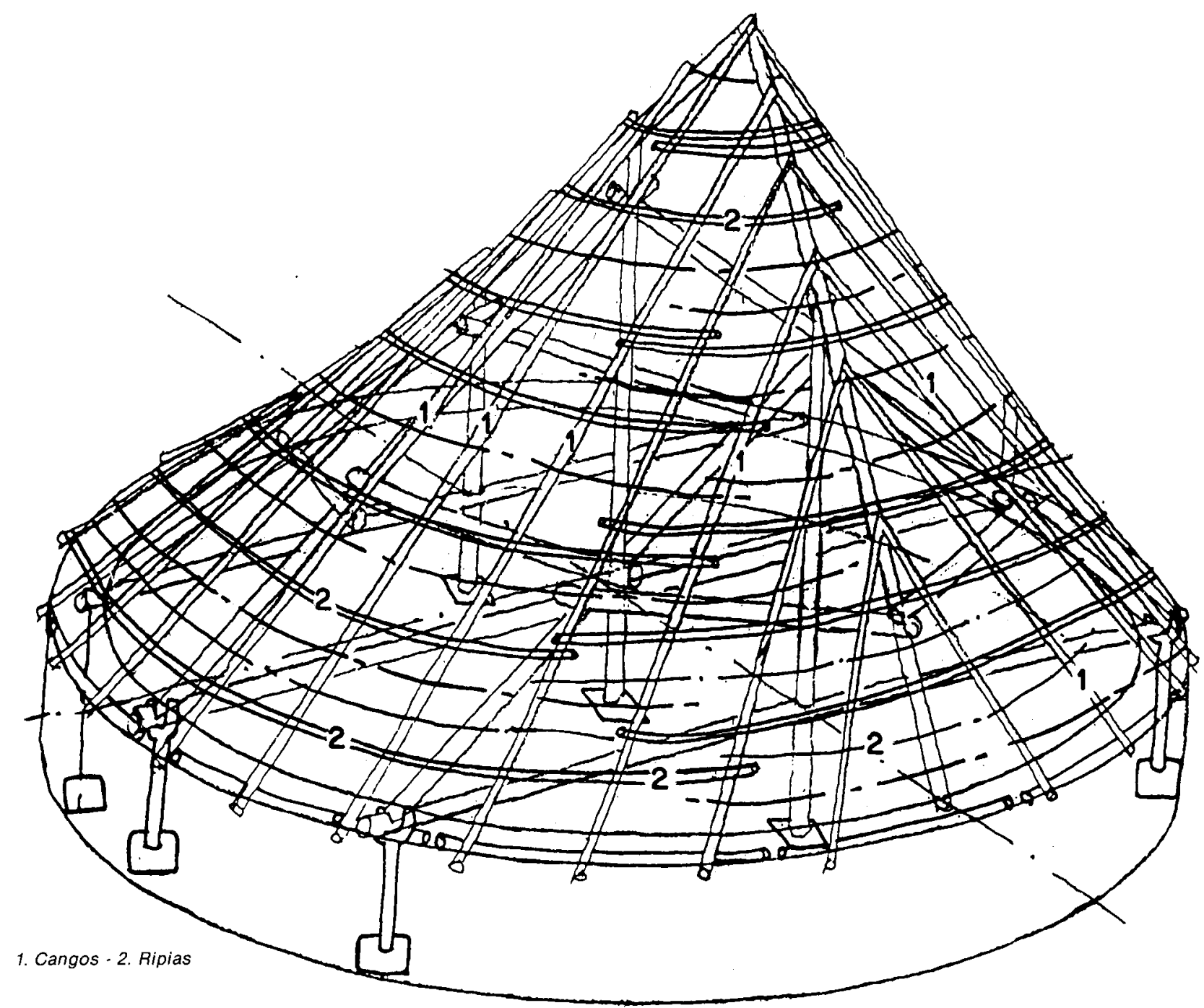

do la paja y atando a la ripia y a la hilera anterior, siempre desde la base hasta la cumbre. La vida de un techo de paja puede ser de 20 años, reponiendo cada 4 ó 5 años paja en los sitios donde se haya deteriorado. De esta manera, después de la primera vez, un techo nunca se vuelve a hacer entero. Una vez terminada la operación de techar, se tapan con fachuzos (gavillas de paja) todos los agujeros y aberturas existentes entre el muro y la parte inferior del techo.

\section{Distribución en planta}

El piso de la construcción es la superficie natural del terreno, apelmazada y dura. Está dividido en dos partes principales, la dedicada a vivienda, y la cuadra del ganado mayor, Ilamada estravariza. Esta, suele ocupar algo más de la mitad de la planta, y tiene una puerta grande de dos hojas, por donde entra el ganado y se mete el carro. La parte dedicadá a vivienda y otros compartimentos se situa en un plano, ligeramente más alto que la cuadra, y está separada de ésta por un tabique de tablas que coincide con la viga madre de la $t i$ xeira central. En este tabique hay una o dos puertas que acceden a la cuadra. La vivienda no suele tener más que un vano, la puerta exterior. Esta, es de una sola hoja dividida por la mitad en sentido horizontal, de manera que se pueda abrir únicamente la parte superior, con el fin de que entre la luz de fuera o salga el humo cuan. do se enciende el fuego. A algunas pallozas "modernizadas" se les han abierto ventanos en el muro, y a veces, salida de humos en el techo. La puerta exterior da acceso a una sola estancia formada por el astrago y la lareira.

El astrago es la entrada de la casa y el lugar por donde se circula. Permite el acceso a la cuadra mayor y a unos compartimentos, hechos con tablas, situados entre el 


\section{ESTRUCTURA SIN ESTEOS, BASADA EN UN TIXEIRADO CON FORCADOS DE FUERZA}

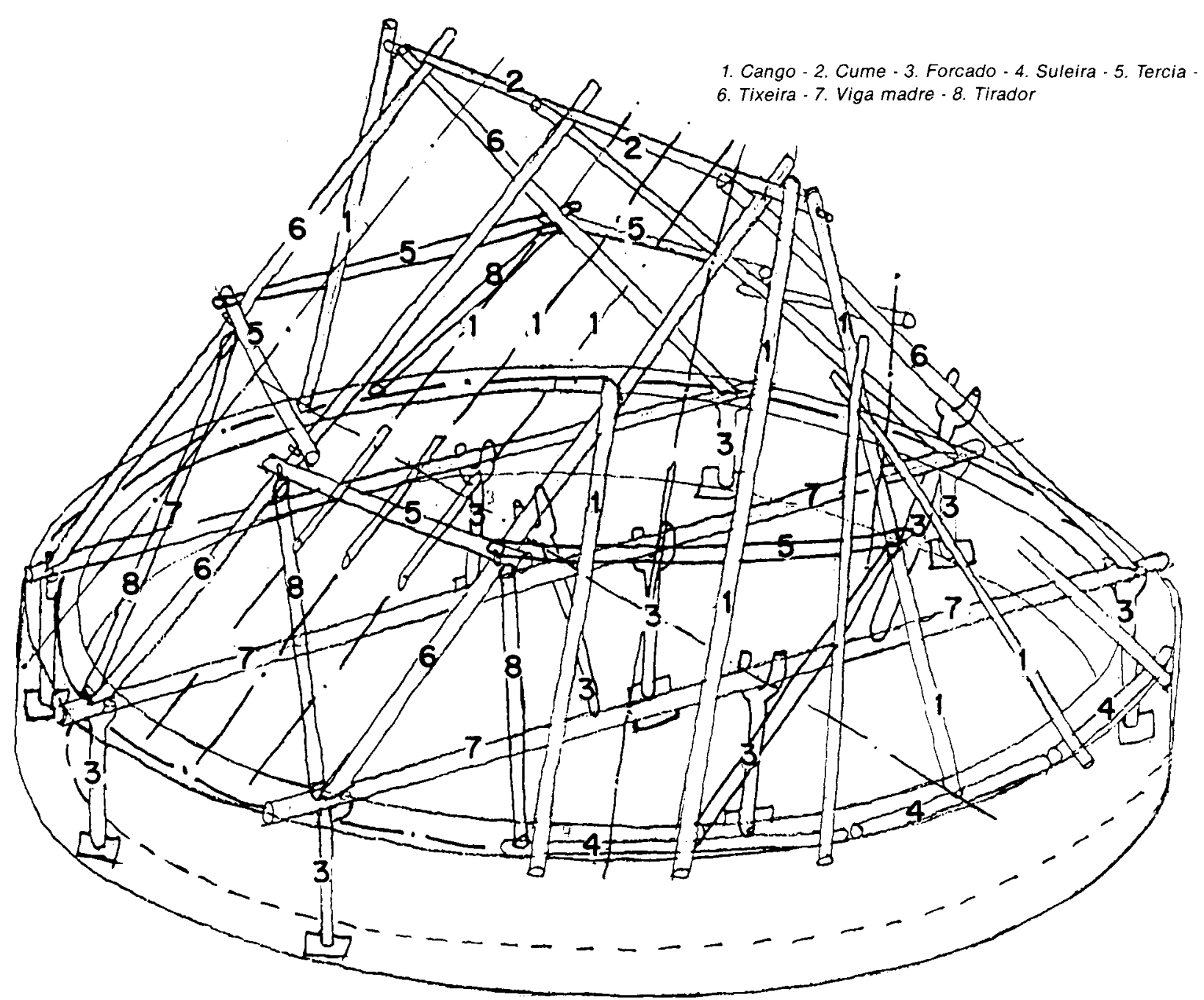

Palloza caracteristica de Campo del Agua, Balouta y El Cebrero, aunque también las hay en los demás pueblos. Los esteos desaparecen en algunas de ellas. El cume o encumia es uno solo, horizontal al suelo. La multiplicación de tixeiras permite hacer pallozas más grandes, que adoptan la forma alargada o rectangular con ángulos redondeados.

horno y la puerta exterior. Estos compartimentos, denominados riqueisos, son de pequeñas dimensiones $(2 \times 1 \mathrm{~m})$ y sirven para meter ciertos animales, o para guardar leña o aperos de labranza.

La lareira, ocupa el centro de la vivienda y es donde el campesino hace su vida alrededor del fuego. En el centro de la lareira hay unas losas de pizarra, de grandes dimensiones, sobre las que se enciende el fuego. Encima del fuego, enganchado en la preganza, está el pote, donde se preparan los caldos. El pote es un recipiente de hierro, redondo y de boca estrecha. Está equipado de tres pies, lo cual posibilita su colocación directamente sobre el suelo. La preganza o garmalleira es una cadena con ganchos que permite colocar el pote a la altura deseada. La garmalleira cuelga del cainzo. En torno al fuego se sitúan los escanos, bancos grandes con respaldo y cajón. Puede haber dos o tres, y sirven, también, para dormir alrededor del fuego. Los es. canos tienen, a veces, una parte que se baja y sirve de mesa.

Frente a la lareira, contra el muro exterior de la casa, está el horno. Este, está construido con la misma piedra que el muro y tiene una cúpula de barro. El horno está formado por dos partes principales: la boca, y la fornela. La boca tiene en la parte superior una piedra - losa en forma de visera, llamada tornalumes, que impide que las llamas o chispas del fuego suban hacia el techo. En la parte inferior del horno está la fornela, lugar donde se depositan las cenizas.

Detrás de la lareira, entre la cuadra y el muro exterior, se sitúa la alcoba. Esta, se asemeja a un cajón de grandes dimensiones con una puerta.

El mobiliario de que dispone la familia es escaso, únicamente el imprescindible para sus necesidades. 


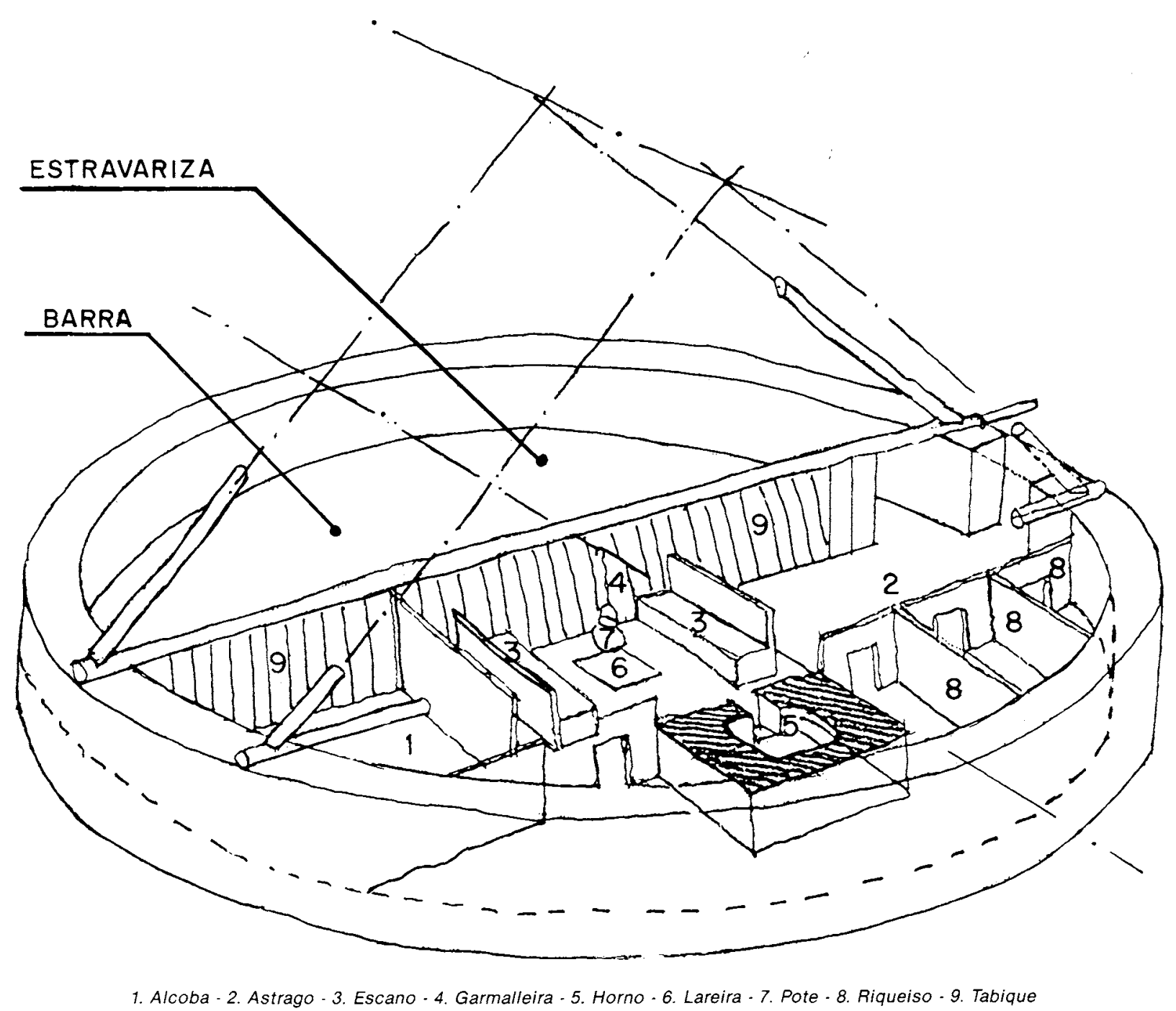

El desván lo forman: la barra, la barrela y el cainzo. La barra, es el sobrado entre la cuadra mayor y el techo de la palloza, en ella, almacenan la hierba seca para el invierno. Suele tener una falsa buhardilla, por la cual se mete la hierba: una vez realizada esta operación, se condena definitivamente. Se accede a la barra por una escalera de mano situada en el astrago. En el verano, o cuando hay invitados, la barra sirve también como dormitorio. Al sobrado situado encima de los riqueisos se le llama barrela, y en él se almacena la leña para el invierno.

A la misma altura que la barra, encima de la lareira, se situa el cainzo. Este, consta de dos vigas paralelas, las gameiras, un entrelazado de varas entre las vigas, y por encima, unas losas que impiden que las chispas del fuego suban hasta el techo. El cainzo sirve para secar las castañas.

\section{FACTORES QUE CONDICIONAN EL HABITAT}

\section{Materiales e influencias en la construcción}

Los materiales que se tienen a mano y la capacidad técnica de los constructores son factores que hay que tener en cuenta a la hora de hacer un estudio sobre un tema de arquitectura popular. En la sierra de Ancares, como en otras zonas de montaña, hasta hace unos treinta años, solamente se utilizaban los materiales existentes en la zona. El único medio de transporte que se conocia era el carro de bueyes.

Los dos tipos de roca que se encuentra en los Ancares son el granito, en la parte occidental, y la pizarra en la parte oriental. En cada pueblo se ha echado mano de la roca existente en el pueblo mismo o en sus alrededores. 


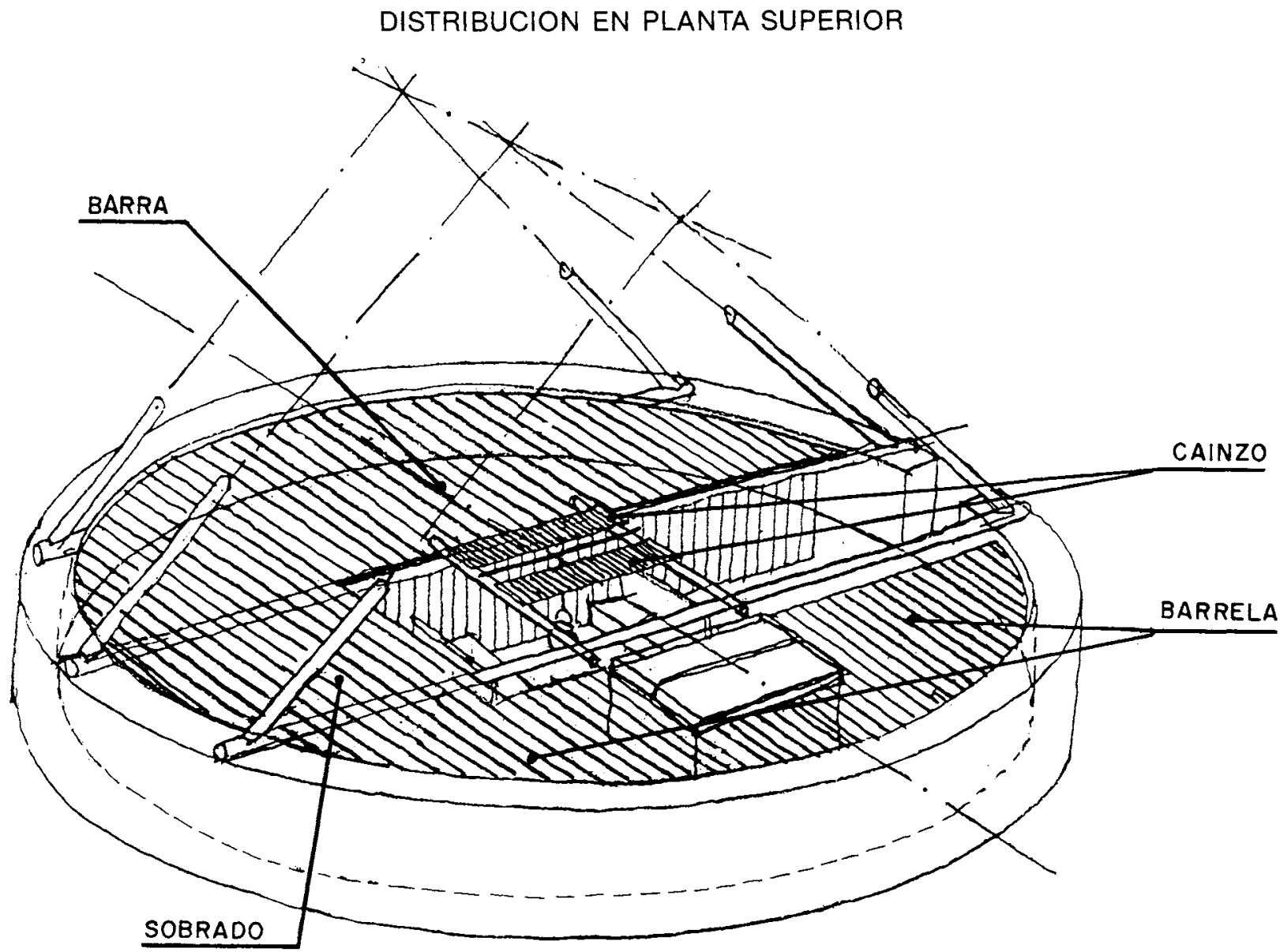

Por este motivo, podemos constatar la diferencia de piedra empleada, de un pueblo a otro, aún cuando la distancia que les separa no es más de ocho o diez kilómetros.

En los Ancares siempre hubo gran abundancia de roble y castaño, madera excelente para la construcción. Esto fue general en todo el noroeste de España, pero en muchas regiones las enfermedades y la mano del hombre acabaron con estos árboles de hoja caduca. En los años 40 y 50 la Renfe llevó a cabo cortes masivos de robles destinados a hacer traviesas para el ferrocarril. El desastre ecológico fue considerable y sus efectos se notan todavía hoy.

El tercer elemento primordial que se necesita para construir una palloza es la paja de centeno. El centeno fue siempre el principal cultivo de la región. Se sembraba en las lomas de los montes alrededor de los pueblos y aldeas. Constituyó durante siglos la base de la alimentación humana, al mismo tiempo que utilizaban la paja para techar sus casas. El uso de la paja es el mayor elemento condicional de la forma de la palloza, puesto que su flexibilidad y fácil manejo hacen posible una pendiente en el techo que oscila entre 40 y 60 grados. Esta pendiente es necesaria para impedir que la nieve pare en el techo, lo cual produciría infiltracio- nes de agua. Por esta razón, mientras hubo suficiente producción de centeno, la paja no escaseó, pero, el fenómeno de la emigración, primero, y la introducción de otros cereales importados, produjo una disminución considerable del cultivo del centeno. En los últimos años muchos campesinos no han tenido paja suficiente para reparar las goteras de sus pallozas. En las campañas de restauración que se han llevado a cabo des. de hace diez años, han tenido que traer la paja de fuera. Por consiguiente, podemos afirmar que la superviven. cia de la palloza ha estado condicionada por los mate. riales existentes en sus al rededores y necesarios para su construcción. Una vez que uno de estos elementos - la paja en este caso- escasea, comienzan a introducirse en la región nuevos materiales más duraderos: las losas de pizarra para hacer los tejados, el ladrillo, el cemento, etc., y nuevas técnicas de construcción. Todo esto ha producido en los últimos 50 años un cambio importante en cuanto a la tradición en la manera de construir, cuya consecuencia más palpable ha sido la paulatina desaparición de las pallozas.

\section{Adaptación de la palloza al medio natural}

El clima de la Cordillera Cantábrica es muy severo. Los principales problemas son las bajas temperaturas, el 


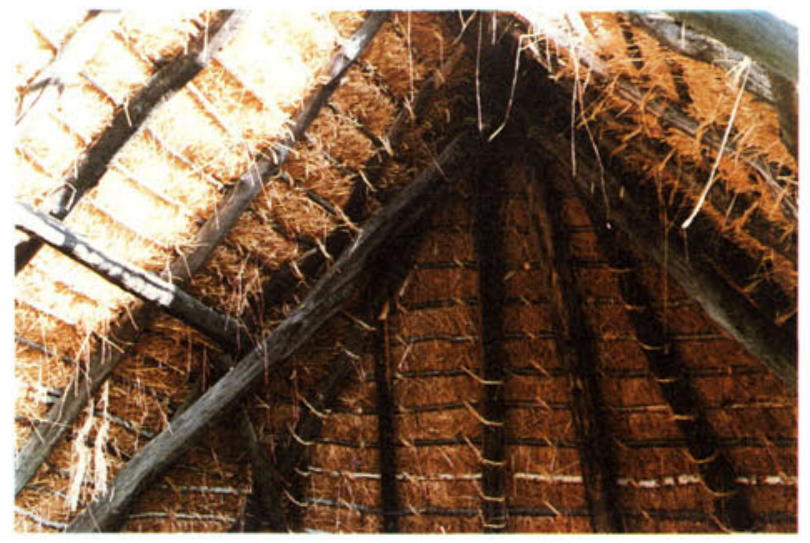

Aspecto de los atados a las ripias y a los cangos.

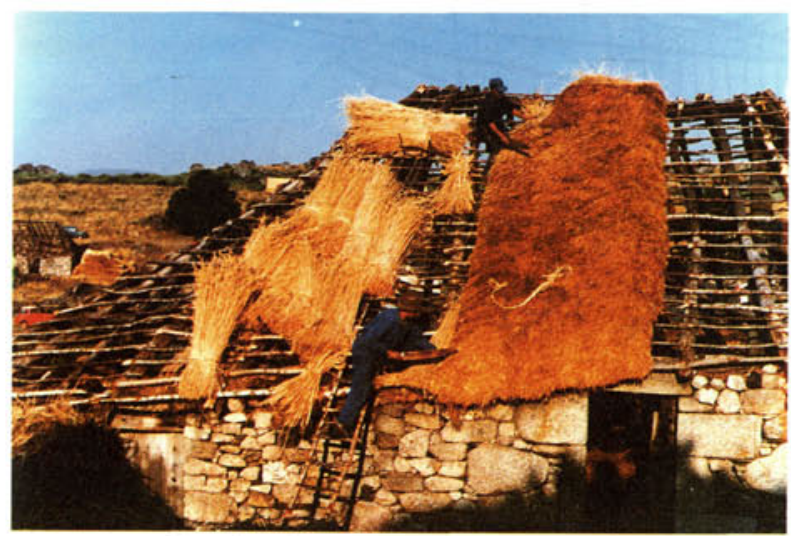

Terminando y empezando una andada.

viento y la nieve. Pero, como ocurre a menudo con estos tipos de construcción que evolucionaron y han hecho sus pruebas a través de los siglos, la palloza es un hábitat perfectamente adaptado al terreno y al clima. A propósito de esta adaptación geográfica, Angel del Castillo decía lo siguiente en su primer artículo sobre las pallozas:

"Tierras las del Cebrero y Ancares extraordinariamente montañosas, envueltas por las nieblas aún en los dias más hermosos del estio, y cubiertas en gran parte del año por las nieves del invierno, tienen que ser viviendas sumamente resguardadas de los fríos y las aguas; y nada más a propósito para defenderse de los unos y las otras, que las típicas pallozas, convertidas por su forma más o menos circular y por lo cónico de su cubierta, en un perfecto reflector del calor que despide el hogar, levantado casi siempre en el centro y que hace de ellas un horno donde se mantiene una temperatura constante de 14 grados, cuando fuera sopla el cierzo a 11 grados bajo cero y la nieve lo cubre todo con su blanco sudario".

Esta cita de Angel del Castillo refleja perfectamente la extraordinaria adaptación de la palloza al medio ambiente. Los paisanos del Cebrero (pueblo de pallozas situado a la altura del puerto de Piedrafita en la N. VI) se quejaban (cuando se trasladaron de las pallozas a casas rectangulares modernas construídas para ellos

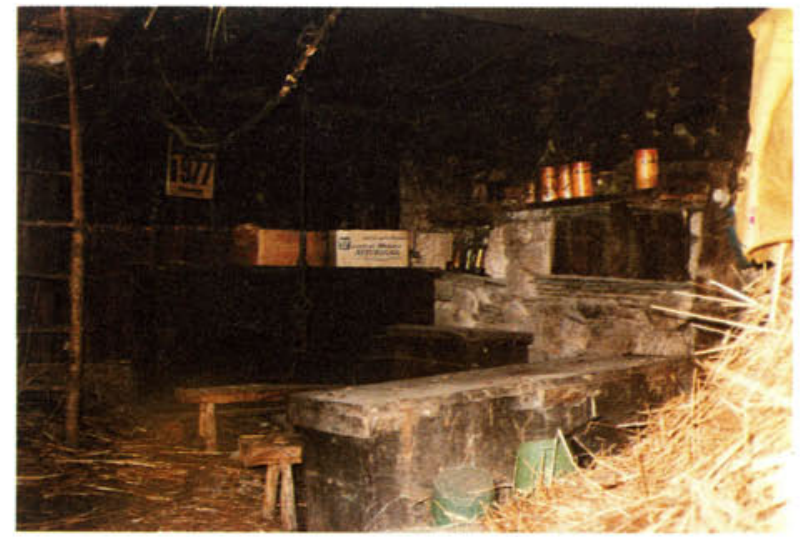

La Ceira. Interior de una palloza.

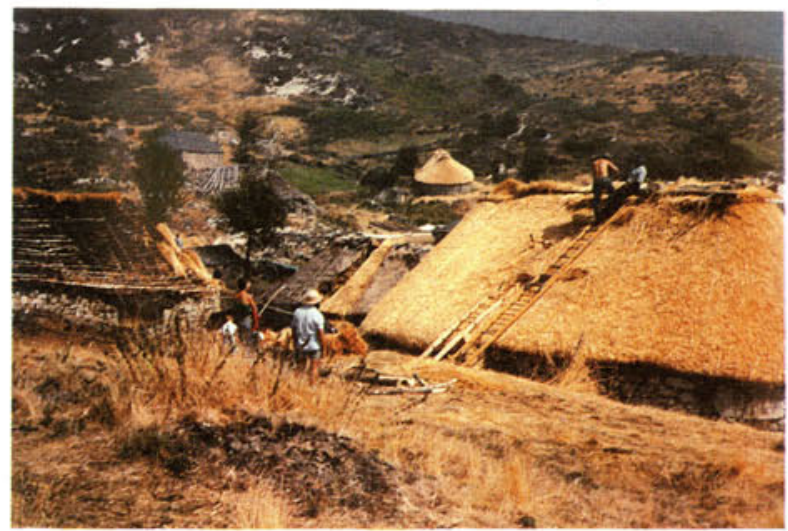

Encumiando. El techo está terminado.

por el Estado en los años sesenta) de que las nuevas casas no eran tan calientes como las pallozas. Hay que tener en cuenta el calor que proporcionan los animales viviendo bajo el mismo techo que las personas, y el excelente aislante que es la hierba seca almacenada en la barra. A menudo, en el invierno, algunas aldeas quedan incomunicadas, a causa de la nieve, durante varias semanas. En estas condiciones, la vida autosuficiente dentro de la palloza no puede ser interrumpida por las inclemencias del tiempo. Alli todo está bajo el mismo techo, viveres, animales, hierba para alimentarlos y todo lo que la familia necesita.

La lluvia que cae con regularidad en cualquier época del año, en esta parte de España, es una ventaja para la palloza, pues impide que, incluso en el verano, la paja del techo llegue a secar demasiado con el consiguiente peligro de que pueda arder.

\section{TESTIMONIOS Y OPINIONES}

\section{Origen de las formas redondas}

Uno de los aspectos más llamativos de una palloza es su forma redonda u oval. Esta característica ha originado una gran divergencia de interpretaciones entre los estudiosos del tema. ¿Por qué construian en redondo? ¿Cuál es su origen?

http://informesdelaconstruccion.revistas.csic.es 
Como respuesta a la primera pregunta me ha llamado la atención la opinión de algunos autores. López Cuevillas atribuye las formas redondeadas a la "torpeza del constructor",(1) V. Risco atribuye la pervivencia de la planta circular u oval a "una tendencia inconsciente de raza de un esquema tradicional", (2) y en opinión de Eugenio Salazar "viven en casas redondas porque, para que quepa la ruindad de sus moradores, la figura redonda es la más capaz...." (3) Teorias que, como esta última no pueden ser tomadas en serio.

Autores más científicos, como J. Caro Baroja, consideran las construcciones circulares de los castros y las actuales como una evolución de las primitivas chozas del período Neolítico construidas con substancias vegetales perecederas. Las compara con otras construcciones palafíticas, es decir, casas construidas sobre estacas en lagos o en seco, que pudieron existir en Galicia, basandose en la existencia, todavia hoy, de hórreos y cabazos. ${ }^{(4)}$ Luengo Martínez se inclina, también, por el origen autóctono, diciendo que:

"Nacieron éstas de la evolución de las primitivas cabañas del período Neolítico con planta circular y paredes y techumbres de ramaje y barro, cuyos elementos pervivieron durante la Edad del Bronce, Ilegando a entroncar en la cultura céltica del Noroeste Hispano..., que originó la cultura castreña." (5)

Estas tesis son corroboradas por los especialistas de la cultura castreña gracias a los hallazgos arqueológicos. Romero Masiá, dice "en diversas excavaciones de castros se descubrieron restos de fragmentos de barro o arcilla que presentaban huellas de palos y tablas imbricadas", y esto, "hasta cinco niveles diferentes, separados por capas de carbones y cenizas que evidencian otros tantos incendios, tan sólo el nivel superior, en el quinto, se detectó la presencia de casas de piedra...." Más adelante continúa diciendo que "la presencia de las casas de piedra viene acompañada de materiales que presentan una presencia, o al menos influencia del mundo de Roma".(6)

La otra tesis, la más extendida, es la que considera a las construcciones redondas como producto de la actividad cultural de los pueblos de raza celta. Su máximo defensor es Bosch Gimpera. Según este autor, los pueblos que dominaron el noroeste peninsular, antes de la llegada de los romanos, eran de origen celta. Al decir esto, se basa en los escritos de los antiguos, Avieno, Estrabón, y en los trabajos sobre las leyendas ofiolátricas, relativas a los castros, estudiadas por Cuevillas y Bonza Brey.(7)

Asi pues, dado que la mayoría de los especialistas de la casa redonda consideran la palloza como una pervivencia de los castros, quedaria por esclarecer si estos son de origen celta o no. Para justificar el origen castreño de la palloza se basan en que la zona de exten-

\section{DETALLE DE MACHIHEMBRADO DE LOS CANGOS}

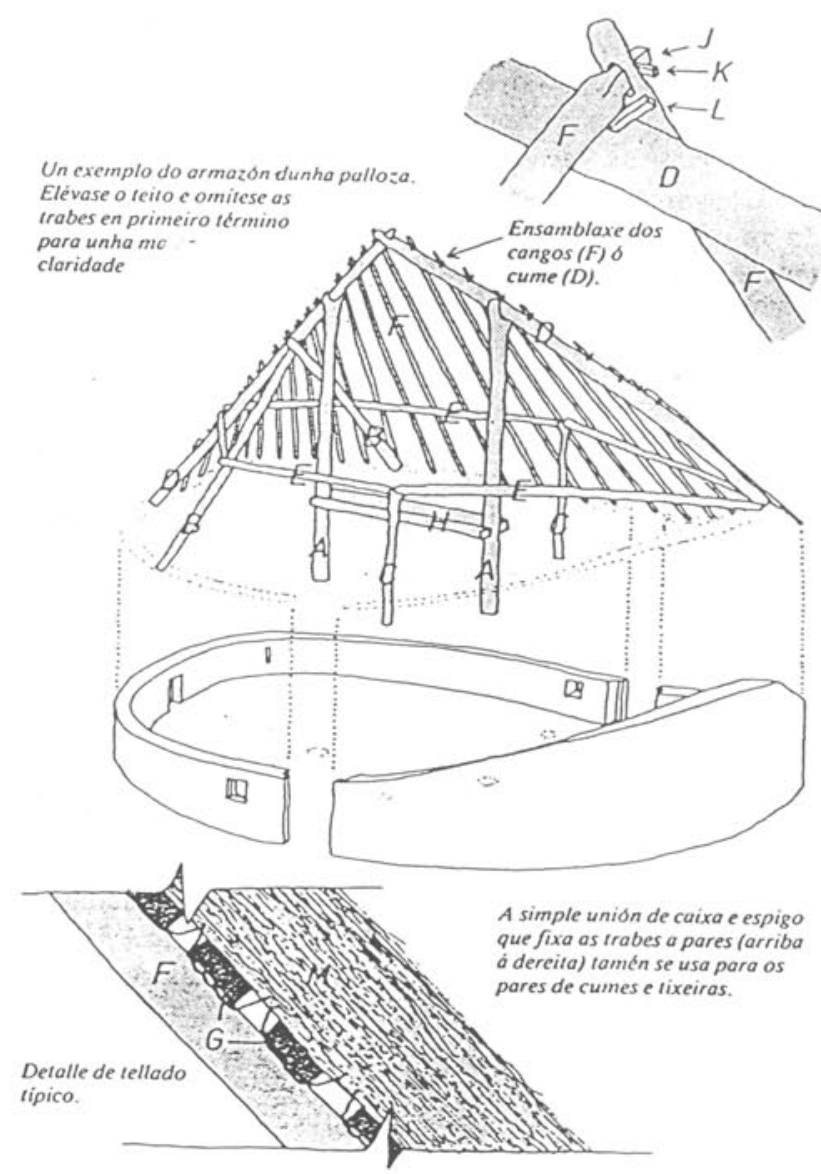

M. GIMSON, As Pallozas, Vigo, Galaxia 1983.

sión de ésta coincide con la zona de aparición de los castros. Garcia y Bellido califica las pallozas de "fósiles de la casa castreña"'(8) y A. del Castillo, después de haberse inclinado por el origen celta, rectifica su opinión diciendo finalmente que nada prueba que sean de origen exclusivamente celta ya que la construcción circular con muros muy bajos y grandes techumbres es una característica de los pueblos primitivos sedentarios que existieron en diversas partes del viejo continente.(9)

\section{Otras construcciones vernáculas concomitantes}

Las pallozas no son las únicas casas circulares que se encuentran todavía en la Península Ibérica. Hay otros grupos de construcciones circulares subsistentes, especialmente a lo largo de la frontera entre España y Portugal. En la mayoría de los casos, se trata de chozas o bohios que sirven de cobijo a los pastores(10). Pero las analogías pueden ser solamente superficiales y seria un error deducir que están necesariamente relacionadas con las pallozas. Para establecer alguna relación habría que hacer un análisis minucioso de los detalles 


\section{EVOLUCION DE LAS PLANTAS SEGUN EL TIPO DE ESTRUCTURA. CLASIFICACION}
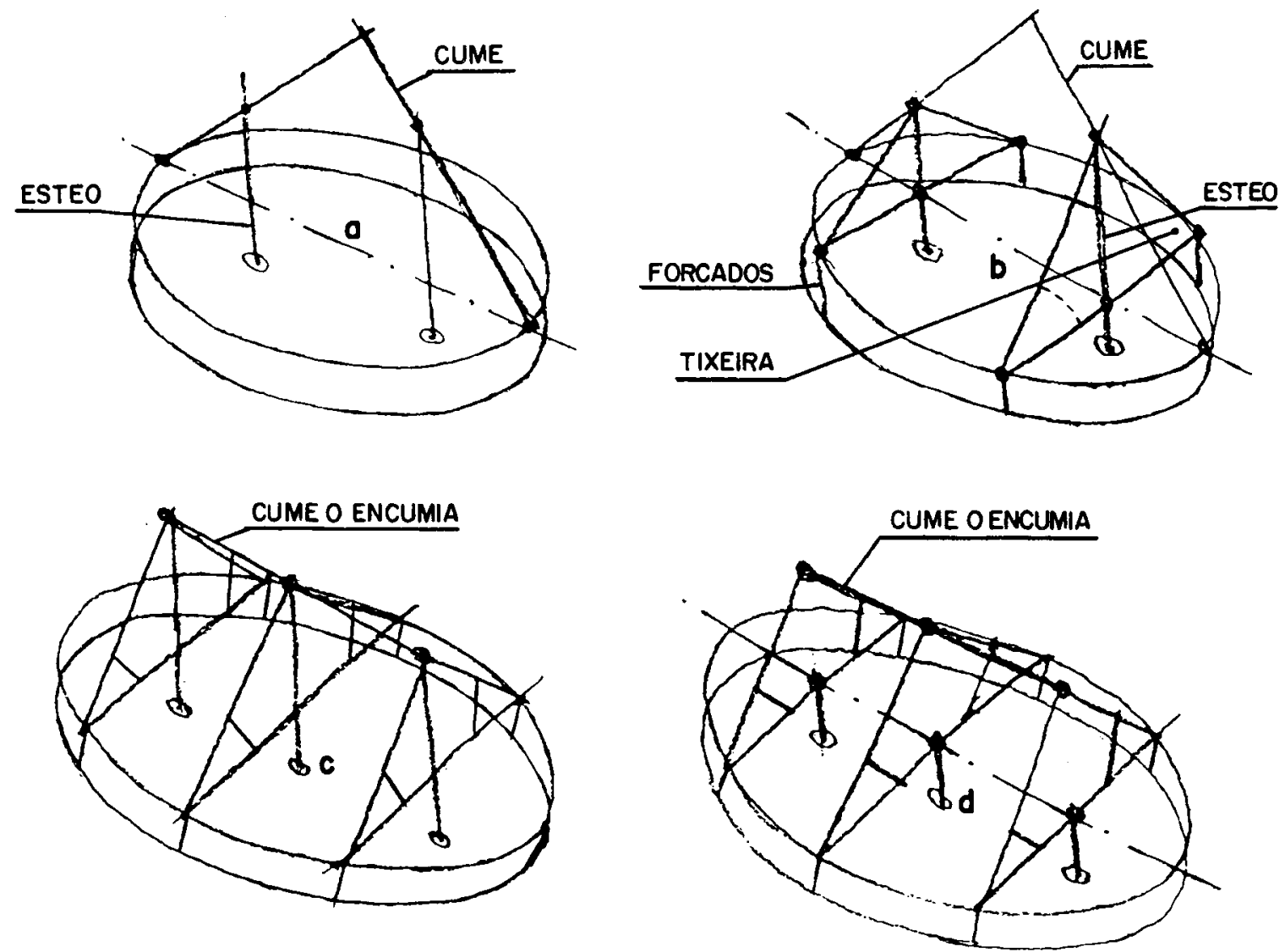

a) Palloza sin tixeiras. b) Aparecen las tixeiras. c) La palloza crece en sentido longitudinal aumentando el número de tixeiras. El cume o encumia se coloca horizontal al suelo. d) Desaparecen los esteos.

de construcción, distribución interior, agrupamientos y todos los demás factores. Puede resultar más provechoso considerar las analogías con otros tipos de construcciones vernáculas del noroeste, teniendo siempre presente que los restos arqueológicos de la cultura castreña solamente se han €ncontrado en el noroeste de España y norte de Portugal.

Como hemos dicho, en el capítulo consagrado a la descripción de la palloza, lo que caracteriza a esta construcción es la particularidad autoportante del armazón, es decir, el entramado de vigas maestras y postes que sostienen la cubierta reposan directamente sobre el suelo. El papel del muro consiste en cerrar el espacio que rodea la base del armazón.

Esta particularidad me conduce a considerar la palloza como el tipo más primitivo de hábitat que en otros tiempos era común en toda la región.

El segundo tipo, que algunos autores Ilaman cabañas o chozas rectangulares(11), es muy similar a la palloza, sobre todo en cuanto a los materiales empleados, distribución y fines del hábitat. La diferencia estriba en la construcción. En este tipo de casas la estructura del armazón de la cubierta ya no es autoportante. Las vigas madres de las tixeiras se apoyan en los muros exteriores. Estos son de gran espesor $(1 \mathrm{~m})$ y soportan el peso de la cubierta. Las plantas son rectangulares con esquinas vivas. Suelen tener, también, más vanos, dos puertas en la parte dedicada a vivienda de las personas, dos buhardillas y dos ventanos. Algunas tienen un porche o techo avanzado, delante de la puerta de la cuadra, donde guardan el carro y el arado. El techo sigue siendo de paja, pero a cuatro aguas, y con los lados menores casi formando ángulos. Las más modernas tienen, ya, tejados de pizarra a dos aguas y los muros laterales más altos. Este tipo de casas abundan más en los valles bajos que en las lomas o zonas altas de montaña. En otras épocas se extendió mucho por las zonas Ilanas de la región. En la comarca del Bierzo, limitrofe con los Ancares, es indudable que varios pueblos y barrios tomaron su nombre de este tipo de casas, como Cabañas, Cabañararas, Cabañinas, etc. Mientras que la palloza es una casa insulana, no pega con ninguna otra, las casas rectangulares, a veces, se agrupan formando manzanas.

El tercer tipo, es la casa serrana. La casa serrana co. mún de las montañas del noroeste es cuadrada o rec- 
tangular, dedicando la planta baja a cuadras y almacén del campesino. La cubierta es de pizarra, generalmente a dos aguas. En el piso alto está la vivienda con una parte dedicada a cocina, que tiene chimenea y horno, y el resto son habitaciones. Estas casas tienen en su parte delantera una gran solana sostenida por las vigas que sobresalen de la construcción. Se cierra la solana con tablas bastante altas con el fin de contrarrestar el frío y las nieves que azotan en el invierno. El tener los animales en la planta baja es un buen sistema de calefacción para la casa. Este tipo de casa pertenece ya a una sociedad agrícola y ganadera más desarrollada que la de la palloza, y que necesita espacios amplios para su ganado y sus aperos de labranza.

Después de haber analizado las similitudes y diferencias que unen o separan este tipo de construcciones, cabe preguntarnos si los dos tipos de casa de que acabamos de hablar son una evolución de la palloza o, al contrario, constituyen una ruptura. Tenemos que tener en cuenta que los romanos introdujeron en la península muchas técnicas nuevas de construcción que revolucionaron los conocimientos de los pobladores de la peninsula. Estas, trajeron como consecuencia la generalización de los espacios cuadrados y rectangulares. Así pues, me inclino por la hipótesis de la ruptura en cuanto a la concepción de la forma del espacio. Sin embargo, por lo que respecta a la distribución de los diferentes compartimentos dentro del espacio, pienso que ha habido una evolución de la palloza hacia las casas de labranza que conocemos actualmente en el noroeste. La idea del ganado que se guarda bajo el mismo techo que sus propietarios sigue intacta.

Estoy de acuerdo con Leopoldo Torres Balbas cuando dice que las pallozas "parecen ser ejemplos de un tipo primitivo de morada que en otros tiempos se encontraba por toda la región"'(12). Queda mucho trabajo por hacer para comprobar esta teoría, estudiando testimonios arqueológicos, testimonios documentales, y sobre todo investigar de manera exhaustiva las construc. ciones existentes. Dados los testimonios, que conoce-

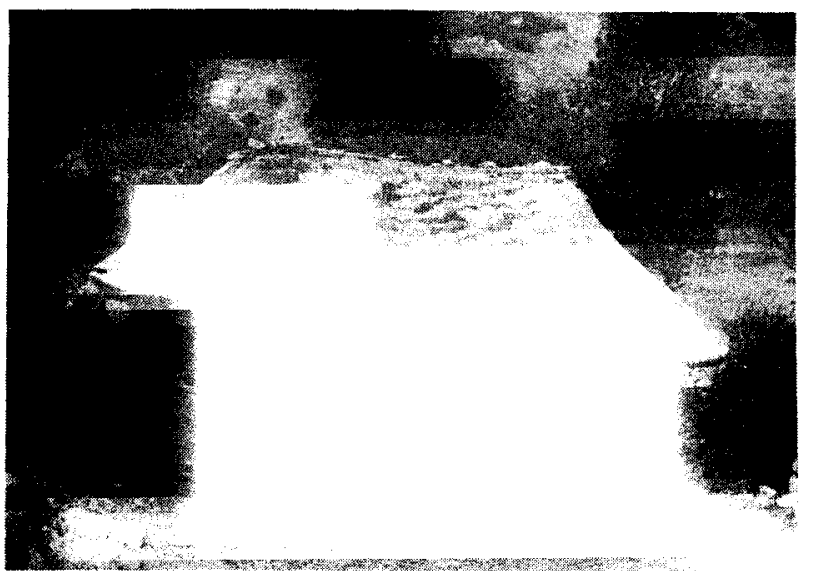

Palloza oval de Campo del Agua.

(c) Consejo Superior de Investigaciones Científicas Licencia Creative Commons 3.0 España (by-nc) mos, parece ser que el tipo de casa más antiguo del noroeste fue la casa redonda, cuyo descendiente más directo, que ha llegado hasta nosotros, es la palloza.

\section{Restauración y recuperación}

Las primeras restauraciones se hicieron en la aldea de El Cebrero, en la vertiente lucense, situada a 8 kilómetros del puerto de Piedrafita del Cebrero, en la carretera que va al monasterio de Samos. El puerto de Piedrafita se situa en la N. VI y es el límite de las provincias de Lugo y León. Estas restauraciones se realizaron allá por los años sesenta. El gobierno construyó, para los vecinos que lo deseaban, casas más modernas al lado de las pallozas. Se restauraron unas doce pallozas y en una de ellas se hizo un museo con mobiliario y utensilios propios de la palloza. Las demás, sus dueños las siguen utilizando como cuadra y pajar. Cuando se mudaron de casa, los habitantes se quejaban de que las nuevas casas eran más frías que las pallozas. Las personas que quieran visitar la palloza museo deberán dirigirse a la hospedería que hay en el pueblo.

El segundo pueblo donde se hicieron restauraciones y mejoras fue Piornedo situado, como El Cebrero, en la vertiente lucense. En Piornedo, las casas, en sí mis. mas, estaban bastante bien conservadas, ya que, en el pueblo había todavia bastantes vecinos, se cultivaba centeno y, ellos mismos se ocupaban de conservarlas en buen estado. Lo que se hizo, a principios de los setenta, fueron principalmente reformas como la traida del agua corriente, el alcantarillado y el pavimentado de las calles con piedras de granito. Hay que señalar que, mezcladas con las pallozas, existen casas de planta baja y piso.

Las obras fueron realizadas por la Diputación Provincial. En los últimos diez años, al abandonarse el culti. vo del centeno y dado el deterioro de algunas pallozas abandonadas, intervino de nuevo la Diputación, aportando la paja y otros materiales necesarios para la restauración. El trabajo lo hicieron los vecinos.

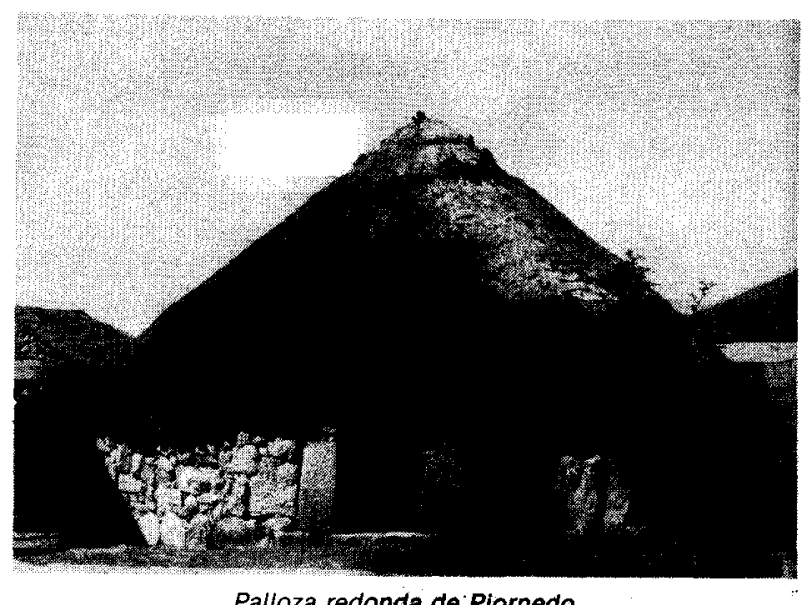

http://informesdelaconstruccion.revistas.csic.es 
Desde hace diez años se habla de construir un pueblo nuevo al lado del actual, para los habitantes de Piornedo, con el fin de que éste sea conservado tal y como era antiguamente y dedicarlo a museo. Esto, por el momento no ha sido posible debido a que los vecinos y la administración no se han puesto de acuerdo. Mientras tanto, los vecinos han realizado reformas, en sus propiedades, que han roto la armonía arquitectónica del conjunto.

En la vertiente leonesa, la preocupación por la conservación de las pallozas tardó más en llegar. Consecuencia de ello, desde los años sesenta, en que desaparecieron o se abandonaron la mayoría, las pallozas han estado en un total abandono hasta el año 1984, en que la Junta de Castilla y León y la Diputación Provincial decidieron comenzar una campaña de restauración. Muchas pallozas habían desaparecido por causa de incendios. Esto, fue el caso concreto de los pueblos del Suárbol y Suertes, donde en 1961 y 1962 respectivamente, se produjeron sendos incendios que arrasaron, casi totalmente, los dos pueblos. En lugar de las pallozas se reconstruyeron casas rectangulares con tejados de pizarra y, para agravar el futuro de las pallozas, el gobernador civil de la provincia impuso un tributo a las casas que tuviesen techos de paja, por considerarlas insalubres y peligrosas en caso de incendio. Esto, unido al abandono por causa de la emigración, hizo desaparecer en 20 años unas construcciones contra las que no habian podido miles de inviernos.

En 1984, gracias a Miguel Yuma(13), la Junta y la Diputación aprueban el primer plan de restauración. Esta, se empezará en el pueblo de Campo del Agua, en el mes de agosto, a pesar de las reticencias de los dueños, que creían ver en la acción de la administración una maniobra para quedarse con sus casas. Hubo que convencerlos de lo contrario y las obras pudieron comenzar rápidamente, gracias a que el pueblo estaba a punto de quedar deshabitado y que sus vecinos tenían casa en Aira da Pedra, el pueblo de abajo.

Para llevar a cabo el trabajo se contrataron a doce artesanos de la paja, casi los últimos que quedan en este oficio, todos ellos de la zona y con edades que osciIan entre los 50 y los 70 años. La paja se trajo de fuera, del Páramo leonés, ya que es muy poco el centeno que se cultiva en la zona. Hubo que majarla puesto que triIlada no sirve. Hasta la fecha (1986) se llevan gastadas 150 toneladas de paja y todavía no se han terminado de restaurar todas las pallozas de Campo del Agua. Hay que tener en cuenta que el $30 \%$ de la paja se pierde al escolmarla. Por lo que se refiere a la madera y a las piedras, se utilizó lo existente en el lugar.

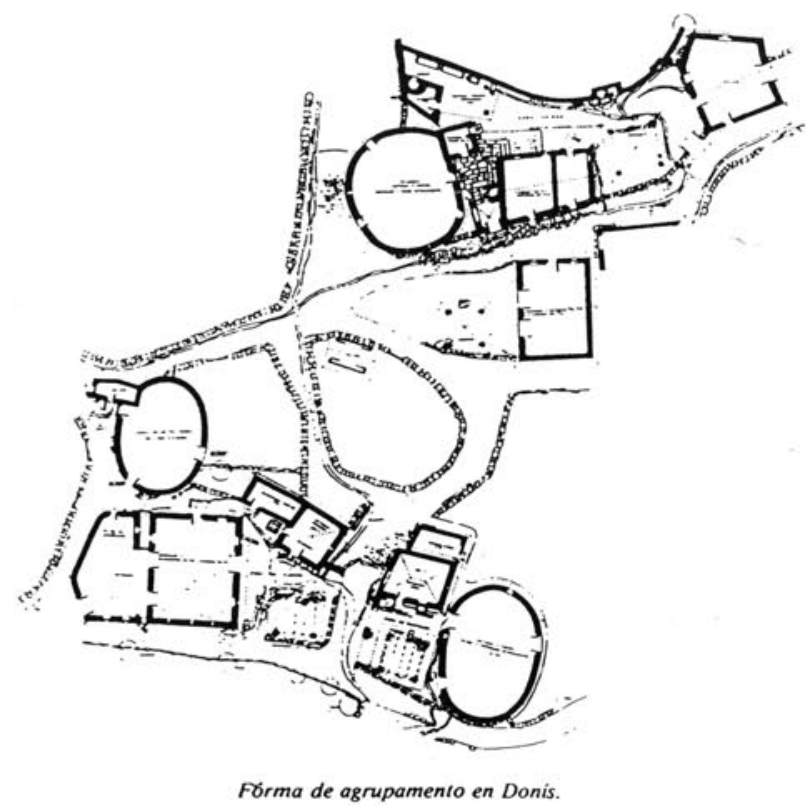

García Fernández, Efren y José Luis, España dibujada, Vol. I, Madrid, 1972.

\section{LEXICO $(*)$}

La etimologia se ha consultado en el Diccionario Crítico Etimológico de J. Corominas (ver bibliografia) y en la Gramática Elemental del Gallego Común de R. Carballo Calero.

ANDADA: Porción de paja que el teitador coloca en el techo, de abajo arriba, atada a éste. La cantidad de paja que lleva un techo se calcula en andadas.

ASTRAGO: Entrada, pasillo, suelo, vestíbulo, Del Lat. ASTRA. CUM, pavimento, J. Corominas.

BARRA: Desván. Sobrado dedicado a guardar la paja o a dormir. Voz prerromana común a todas las lenguas romances menos el romano. J. Corominas.

BARRELA: Barra pequeña.

BOCA: Parte central del horno por donde se mete la leña para calentarlo.

BRINCAYO O BINCAYO: Atadura hecha con pajas. Del celta BRIN. R. Carballo.

CAINZO O CANIZO: Entrenzado de varas en el que se secan Ias castañas. Del Lat. CANICIUM. J. Corominas.

CANGO: Madero de la cubierta al cual se atan o clavan las ripias. Probablemente del céltico CAMBICA. J. Corominas.

CASTROS: Fortificaciones de origen prerromano, situadas generalmente en una pequeña colina. Se descubrieron a principios de este siglo en todo el noroeste de España.

(*) La pronunciación de algunos vocablos varía según los pueblos debido a las influencias del castellano, del gallego y del bable. Igualmente, dos o más vocablos diferentes pueden designar una misma cosa.

http://informesdelaconstruccion.revistas.csic.es 
CASTREÑO, A: Relativo a los castros.

COLMADO: Techo de paja de centeno.

COLMAR: Techar con paja de centeno.

CUELMO: Gavilla de paja de centeno. Perteneciente a alguna lengua indoeuropea, probablemente del céltico. COLMOS. J. Corominas.

CUME: Viga de armar la cubierta. Del Lat. CULMEN-INIS, cumbre del tejado. Parte más alta. J. Corominas.

ENCUMIAR: Terminar de poner la paja sobre el cume. Terminar de techar. Cerrar el techo. Terminar de cubrir con paja la parte más alta del techo.

ESCANO: Banco con respaldo. Del Lat. SCAMNUN. J. Corominas.

ESCOLMAR: Escoger, seleccionar la paja para techar.

ESTEO: Columna de madera. Pie derecho. Perteneciente a la construcción.

ESTRAVARIZA: Cuadra del ganado mayor.

FACHUZOS: Gavillas de paja que se utilizan para tapar los agujeros.

FORCADO: Poste. Perteneciente a la construcción. Palo in cado en el suelo y bifurcado en lo alto. Del Lat. FURCA J. Corominas.

FORNELA: Parte del horno donde se desposita la ceniza. Del Lat. FURNUS. J. Corominas.

GAMEIRAS: Vigas gemelas que sostienen el cainzo.

GARMALLEIRA: Cadena que se engancha en las gameiras y de la cual cuelga el pote. De GARMA, vocablo del noroes te, probablemente prerromano que significa, también, risco, despeñadero. Analogía con la palabra francesa "crémaillère" que significa lo mismo, cadena. J. Corominas.

LAREIRA: Hogar. Del Lat. LAR.

LOUSA: Losa. Piedra plana de pizarra que se coloca sobre el cainzo con el fin de que las chispas del fuego no suban hasta la paja. Del vocablo prerromano LAUSA, de origen incierto. J. Corominas.

MAJAR: Separar el grano de la paja del centeno. Del Lat. MALLEUS. J. Corominas.

MAJADORA: Máquina de majar.

MAYAL: Dos palos unidos entre si por un cuero que les permite articularse. Antiguamente se utilizaba para majar, golpeando el grano.

PALLAZA O PALLOTA: Palloza. término utilizado en casi todos los testimonios documentales antiguos. Yo he preferido utilizar palloza, por ser el término actual.

PINO: Clavo o clavija de madera que se utiliza en los machiembrados. Del vocablo PINA "Cuña", de origen incierto quizás prerromano, conservado en el leonés, y portugués y gallego. J. Corominas.

POTE: Recipiente. Puchero.

PREGANZA: Garmalleira. Término leonés. "Pregar" viene de "plegar", voz prerromana de origen probablemente indoeuropeo.
RIPIA: Palos toscos y delgados, sin serrar, que se clavan o atan a los cangos y, sobre los cuales se dispone y ata la paja. Probablemente del gótico RIBJO "Costilla", vocablo germano eslavo de origen indoeuropeo. J. Corominas.

RIPIADA: Con ripias.

RIPIAR: Poner ripias.

SARRO: Hollin en los Ancares. A veces, se presenta como un betún o barniz duro y fuerte que se adhiere a las maderas u otros objetos. Voz seguramente de origen prerromano. Mismo origen de SARNA. J. Corominas.

SULEIRA: Perteneciente a la construcción. Maderos que rematan el muro y sobre los cuales se apoyan los cangos.

TEITAR: Techar. Cubrir un techo con paja. Del Lat. TEGERE, cubrir. J. Corominas.

TEITADOR: Techador.

TEITELLO: Paleta que utiliza el teitador para touzar la paja

TERCIAS: Maderos de la construcción, situados entre las texeiras, sobre los cuales, se apoyan los cangos.

TIRADOR: Palo de la estructura que sujeta la tixeira. De tirar, quizás de origen prerromano. J. Corominas.

TIXEIRA: Tijera. Perteneciente a la estructura. Vigas en forma de tijera.

TIXEIRADO: Conjunto de tixeiras.

TORNALUNES: Piedra a modo de visera sobre la boca del horno.

TOUZAR: En la operación de techar, se dice cuando se golpea la paja, en su base, con el teitello, con el fin de que no sobresalgan unas pajas de otras. Puede venir del Lat. TUDITIARE. J. Corominas.

VENCELLO: Vencejo. Brincayo.

VILORTIO O VILORTO: Vilorta. Vara fina y flexible que sirve para atar unos maderos a otros. Origen incierto, quizás prerromano y emparentado con el vasco. J. Corominas.

\section{BIBLIOGRAFIA GENERAL}

1. J. L. ALONSO PONGA Y A. DIEGUEZ AYERBE, Etnografia y folklore de las comarcas leonesas; EI Bierzo, León: Ediciones Leonesas, 1984.

2. J. CARO BAROJA, Los pueblos de España, Madrid: Istmo, 1976, I, II.

3. J. CARO BAROJA, Los pueblos del Norte de la Peninsula Ibérica, San Sebastián: Txertoa, 2. ${ }^{a}$ edición, 1973.

4. J. COROMINAS Y J. A. PASCUAL, Diccionario Crítico Etimológico Castellano e Hispano, Madrid: Gredos, 1984.

5. L. CRESPI, "La casa rural desde El Cebrero hasta Piornedo", Conferencia y Reseñas Cientificas de la Real Sociedad Española de Historia Natural, IV, Madrid, 1929.

6. L. FEDUCHI, Itinerarios de arquitectura popular españo la, Barcelona: Blume, 1932, I. 
7. A. GARCIA BELLIDO, "Sobre la extensión actual de la casa redonda en la Península Ibérica", Revista de Dialectologia y Tradiciones Populares, XXIII, Madrid, 1967.

8. M. GIMSON, As Pallozas, Vigo: Galaxia, 1983.

9. A. JORGE DIAS, "Las construcciones circulares del noroeste de la Península Ibérica y las citanias", Cuadernos de Estudios Gallegos, Santiago de Compostela, 1946, VI. Publicación del Instituto Padre Sarmiento.

10. F. KRÜGER, "Las Brañas. Contribución a la historia de las construcciones circulares en la zona astur-galaicoportuguesa", Boletín del Instituto de Estudios Asturianos, n. ${ }^{\circ}$ VIII, Oviedo, 1949.

11. J. M. LUENGO MARTINEZ, La arquitectura popular de los Ancares leoneses, Actas y memorias de la Sociedad Es.' pañola de Antropología, Etnografía y Prehistoria, XXXIII, XXXIV, XXXV, 1960, 61, 62.

12. L. TORRES BALBAS, "La vivienda popular en España", Folklore y Costumbres de España, III, Barcelona, 1949.

13. A. ROMERO MASIA, El hábitat castreño: asentamientos y arquitectura de los castros del noroeste peninsular, Santiago de Compostela, 1976. Publicaciones del Colegio de Arquitectos de Galicia.

14. A. DEL CASTILLO, "Por las montañas de Galicia. Origen y antiguedad de las "Pallazas" del Cebrero", Boletin de la Real Academia Gallega, n. 78 (1913), n. 82 (1914), La Coruña.

\section{NOTAS}

(1) A. LOPEZ CUEVILLAS, "Las habitaciones de los castros", Cuadernos de Estudios Gallegos, V, 1946, p. 21.

(2) V. RISCO, "Estudio etnográfico da terra de Melide", Seminario de Estudos Galegos, Santiago de Compostela: 1933, p. 38.

(3) E. DE SALAZAR, "Cartas de Eugenio de Salazar, vecino y natural de Madrid, escritas a muy particulares amigos suyos", Sociedad de Bibliófilos Españoles, Madrid: 1986, pp. 81-90. Estas cartas se publicaron también en "Epistolario Español", Biblioteca de Autores Españoles de Rivadeneira, LXII, p. 303.

(4) J. CARO BAROJA, Los pueblos de España, Madrid: Ist. mo, 1976, l, pp. 53-55.

(5) J. M. LUENGO MARTINEZ, Esquema de la arquitectura civil en el Bierzo, León: Servicio de Publicaciones de la Excma. Diputación Provincial de León, 1967, pp. 9-10.

(6) A. ROMERO MASIA, El hábitat castreño: asentamientos $y$ arquitectura de los castros del noroeste peninsular. Santiago de Compostela: Servicio de Publicaciones del Colegio de Arquitectos de Galicia, 1976, pp. 51-54.

(7) A. JORGE DIAZ, “Las construcciones circulares del noroeste de la Península lbérica y las citanias", Cuadernos de Estudios Gallegos, Santiago de Compostela: Publicación del Instituto Padre Sarmiento, VI, 1946, pp. 177-179, cita a P. BOSCH-GIMPERA, Etnología de la Península lbérica, Barcelona, 1932.

(8) A. GARCIA Y BELLIDO, "Sobre la extensión actual de la casa redonda, en la Península lbérica", Revista de Dialectologia y Tradiciones Populares, XXIII, Madrid, 1967, p. 41.

(9) A. DEL CASTILLO, "Por las montañas de Galicia. Origen y antiguedad de las "Pallazas" del Cebrero", Boletín de la Real Academia Gallega, año IX, Coruña, abril 1914, $n .^{\circ} 82$.

(10) A. GARCIA BELLIDO, op. cit. Este autor trata en este trabajo todas las construcciones circulares que se extienden por todo el Occidente de la Península Ibérica.

(11) J. M. LUENGO MARTINEZ, op. cit., pp. 10-11.

(12) L. TORRES BALBAS, "La vivienda popular en España", Folklore y Costumbres de España, III, Barcelona; 1949, p. 501.

(13) M. YUMA, ha sido el alma y el promotor de la restauración llevada a cabo en el 84 y 85 en Campo del Agua. Gracias a su labor, los pueblos de Burbia y Aira de Pedra ("Pueblo de abajo" de Campo del Agua) consiguieron la luz eléctrica en el 85.

Dibujos: T. de Champris sobre boceto de F. González. 